\title{
A Phenomenological Study on Online Learning Set-up: Challenges and Coping Mechanisms of Senior High Students
}

\author{
Jean Louise L. Hidalgo ${ }^{a}$, Julia C. Cadavis ${ }^{b}$, Aretha Louise S. Matienzoc ${ }^{c}$, Kristine \\ Karyll T. Lanzarrote ${ }^{\mathrm{d}}$, Eldrette Maurice E. Del Rosario ${ }^{\mathrm{e}}$ \\ a, b, c, d, e Leyte Normal University, P. Paterno St., Tacloban City 6500, Philippines
}

\begin{abstract}
During this pandemic, it is expected that students are to experience challenges in their learning with this new system. Thus, as a way to support themselves in their own homes, they find ways to cope that ease the weight of their challenges. According to Petroski's theory, the impact of the sudden changes of online learning caused by the COVID-19 pandemic forced academic institutions and school faculty to try new learning set up to maintain the learning environment of the students. For many students, the sudden shift in their learning environment challenged their capability to transit from an environment that they are new (or they aren't used to) and make a new experience that contradicted themselves as learners for as they didn't have a choice to become online students. In this study, the researchers determine the different challenges the student participants are facing in this new learning system and their various ways of coping with it. The overall results of this study may benefit our educational system to be aware of the challenges the students are currently experiencing. It may help to support better and more efficient solutions for the teachers and students to fully adapt and significantly benefit and use their highest potential in learning with this new learning modality. This study employs the qualitative method to describe the challenges and coping mechanisms of the students in the Senior High School Department of LNU-ILS. In collecting and analyzing the data, A focus group discussion was held consisting of 5 student participants from the SHS department. The data gathered were then analyzed through a thematic analysis method, which yielded a significant range of challenges experienced by the senior high school students, from their personal, social, technical, and workplace challenges to various coping mechanisms with the said challenges.
\end{abstract}

Keywords: Challenges and Coping Mechanisms; Senior High School; Students; Online Learning; Students.

\section{Introduction}

\subsection{Background of the Study}

Online Learning has long existed among educational systems. Rather than being held in a regular classroom, online learning takes place via the internet and over great distances. Gadgets and devices are widely used in this method of education, the teachers and students interact through the use of the internet and online platforms that would serve as their connections to one another as well as tools that would support the activity of Online Learning.

During this COVID-19 pandemic, the online learning set up has been widely employed for education to make up for the loss of ability in conducting the traditional way of handling classes. The Department of Education (DepEd) reopened classes in both public and private education institutions on October 5th, 2020, for the school year of 2020-2021. Transitioning from face-to-face learning to distance learning, one of which is the online learning set-up. The young generation is now adapting and coping with the challenges they will face ahead from being introduced in a completely new environment for their classes will now be held online. According to the Manila Bulletin, there are five common challenges encountered during online classes: internet connectivity, audio clarity, outdated devices and software, system glitch, and short attention span. The iOptions Ventures Corporation, an independent research firm, conducted a poll on the challenges in distance learning entitled "Philippine Distance Learning Survey" with 6,991 parents, 4,933 teachers, and 7,178 students as respondents. The result stated that the top five challenges are unstable mobile/ internet connection, difficulty in self-studying, distractions (social media, IJRP 2029,91(1), I14-123; doi:10.4719/1JRP1009191220212580 allowance, and lack of available gadgets/ resources. 
In the challenges that the students encounter, students develop coping strategies to overcome these challenges and stressors. The researchers aim to identify and examine the challenges and coping mechanisms of the Senior High School students of the Leyte Normal University - Integrated Laboratory School (LNU-ILS) in an online learning set-up. Through determining the said aspects, the researchers would like to use the results as a way to help the educational system improve and develop a better and more efficient solution for teachers and students in adapting to the new normal way of learning.

\subsection{Research Questions}

This study aims to know the challenges and the coping mechanism of LNU-ILS SHS students in an online learning setup. Specifically, this study seeks to answer the following inquiries:

1. What challenges do the students of LNU-ILS SHS experience in an online learning setup?

2. How do the students cope with these challenges they are experiencing in an online learning setup?

\subsection{Definition of Terms}

Coping mechanism - something a person does to deal with a difficult situation.

Online learning - online learning is education that takes place over the Internet.

Challenges - a new or difficult task that tests someone's ability and skill.

\subsection{Theoretical Framework}

According to Legaspi (2021), the readiness of challenges and coping strategies of an academic institution towards teaching in a new normal revealed that most of the teachers who responded were not yet ready for the academic year 2020-2021 due to the lack of practice and experience in the changes of the new set up. This leads to Petroski's theory that examines the impact of the sudden changes of online learning caused by the COVID-19 pandemic that forced academic institutions and school faculty to try new learning set up to maintain the learning environment of the students. For many students, the sudden shift in their learning environment challenged their capability to transit from an environment that they are new (or they aren't used to) and make a new experience that contradicted themselves as learners as they didn't have a choice to become online students.

\section{Review of Related Literature}

Since this COVID-19 pandemic started, numerous schools worldwide used online education as a new learning set-up. An easy access to knowledge due to self-learning has been an advantage to some students and that's only one of the several advantages. However, even though online learning was the only available solution to this dilemma, both students' and teacher's satisfactions and opinions are significant to have an effective and essential new learning setup. (Elshami, 2021)

\subsection{Challenges in Online Learning}

Many children and teenagers already live-in difficult circumstances at home. The procedures in place to contain the pandemic are likely to have exacerbated these challenging situations. Children may develop and undergo a variety of traumatic experiences. Students experience substantial challenges during the pandemic, including mental health issues, financial distress, loneliness, and difficulties adapting to online learning (Anderson, 2020; Hamza et al., 2020; Rodriguez-Planas, 2020; Browning et al., 2021). 
In a study, Dr. Christopher Yaw Kwaah (2017) has identified that the challenges the distance education students encounter are academic-related (poor performance, lack of learning resources, and academic workload), psychosocial (anxiety, high expectations, and financial problems), and health-related (Illness, sleep problems, and irregular eating habit). A similar study shows a distinct result, as for the challenges E-learners come up against in E-Learning are e-content challenges, coursework challenges, internet access challenges, technology challenges, lack in Information and Communication Technology (ICT) skills and training, interaction and collaboration issues, and personal issues (Kibuku, 2020). Students faced numerous challenges during this pandemic. However, adapting issues, technical issues, academic challenges, communication challenges, and financial support issues were the most critical challenges that students have experienced during this pandemic (Mahyoob, 2020). It is recognized that when the nature of the student's educational experience drastically alters, its impact on this vulnerable population's mental well-being is heightened.

\subsection{Coping Mechanisms}

Coping strategies are ways of handling stressful and troublesome circumstances, and students need to develop coping strategies to manage encountered stress. Coping is described as the thoughts and activities used to deal with stressful events in internal and external aspects. It is a phrase that distinguishes conscious and deliberate act mobilization from 'defense mechanisms,' which are subconscious or unconscious adaptive reactions aimed at reducing or tolerating stress (Algorani \& Gupta, 2021). If students are not able to manage stress, the stressors coming from different kinds of problems can affect the ability of students to perform (Rogers \& Yassin, 2003 cited by Guevarra \& Cimanes, 2017).

This COVID-19 pandemic has hugely affected students, not just on their mental well-being but also the quality of learning they are receiving. In order to succeed in distant learning in the midst of the current crisis, students use a variety of coping mechanisms (Rotas \& Cahapay, 2020). The endorsement of social connection by students during this pandemic, predicted important well-being outcomes like developing new habits, maintaining social relationships, and attempting new activities to compensate for an absence of rigidity (Logel et al., 2021).

Strategies were used to cope with the problems they're facing and according to Barrot (2021), the strategies that was frequently used were resource management and utilization, help-seeking, time management, technical aptitude enhancement, and learning environment control which helped students cope with the challenges they experience on their learning environment at home and technological literacy and competency. According to Lucky (2015), in tough and stressful circumstances, the coping mechanisms that the students perform are reading (novels, inspirational books, and news bulletins), viewing movies and documentaries, playing (sports, music, instruments, and computer games), using social media (Facebook, Twitter, Instagram, etc.), and practicing religion and spirituality. Students that experience distance learning challenges, cope by active coping, positive reframing, emotional and instrumental support, self-distraction, religion venting, denial, and acceptance (Kwaah, 2017). Overall, students that experience difficulties cope by engaging in various and different coping mechanisms to relieve the complexities of reality.

\section{Research Design and Methodology}

This study employs the qualitative method to describe the challenges and coping mechanisms of the students in the Senior High School Department of LNU-ILS. This chapter discusses and describes how the researchers gathered the necessary information applicable and who will be subject to participate in the said study. This chapter explores procedures and methods of data collecting and data analysis techniques, the scope and delimitations of the study that is helpful in processing conclusions. As well as adhere to ethically substantial social and moral values and principles for more collaborative, fair, and respectful work.

\subsection{Research Participant}

The researchers had student participants for the focus group discussion from the senior high school department of LNU-ILS enrolled in the school year 2020-2021. The selection of the student participants was based on their convenience during the data gathering of the study. 


\subsection{Data Gathering Procedure}

This study employs the Focus Group Discussion (FGD) research method. It started with having a small group of respondents asked with open-ended responses conveying thoughts and feelings. Within the FGD, a moderator posed a series of questions intended to gain insight into the way the group views the topic. The FGD moderator posed questions that did not lead group members to provide desired answers of the researcher but rather honest and insightful responses.

\subsection{Data Analysis Technique}

To analyze the gathered data the researchers applied the thematic analysis, which offers a theoretically flexible approach that provides detailed data and is performed through the six processes namely: (1) familiarizing the gathered data, (2) generating the initial codes, (3) searching themes among codes, (4) reviewing themes, (5) defining and naming themes, and (6) producing the final report (Braun \& Clarke, 2006).

\subsection{Scope and Delimitations}

This study consists of personal experiences regarding the participants' challenges and coping mechanisms amidst online learning. This study focuses on LNU-ILS Senior High School students enrolled in the said institution only and no other students from other levels or schools. The topics to be described in this study are the challenges experienced by these students in an online learning set-up and how they cope with the said challenges only.

\subsection{Ethical Considerations}

The participants involved in this study were interviewed with their knowledge. The participant was given a letter of consent and research information regarding the held interview whether they will reject it or not. The researchers protected and refrain from disclosing the personal information of the participants and equally collected and evaluated the notion of the participants. Furthermore, the anonymity of the participants was preserved (Gupta, 2017). 


\section{Results and Discussion}

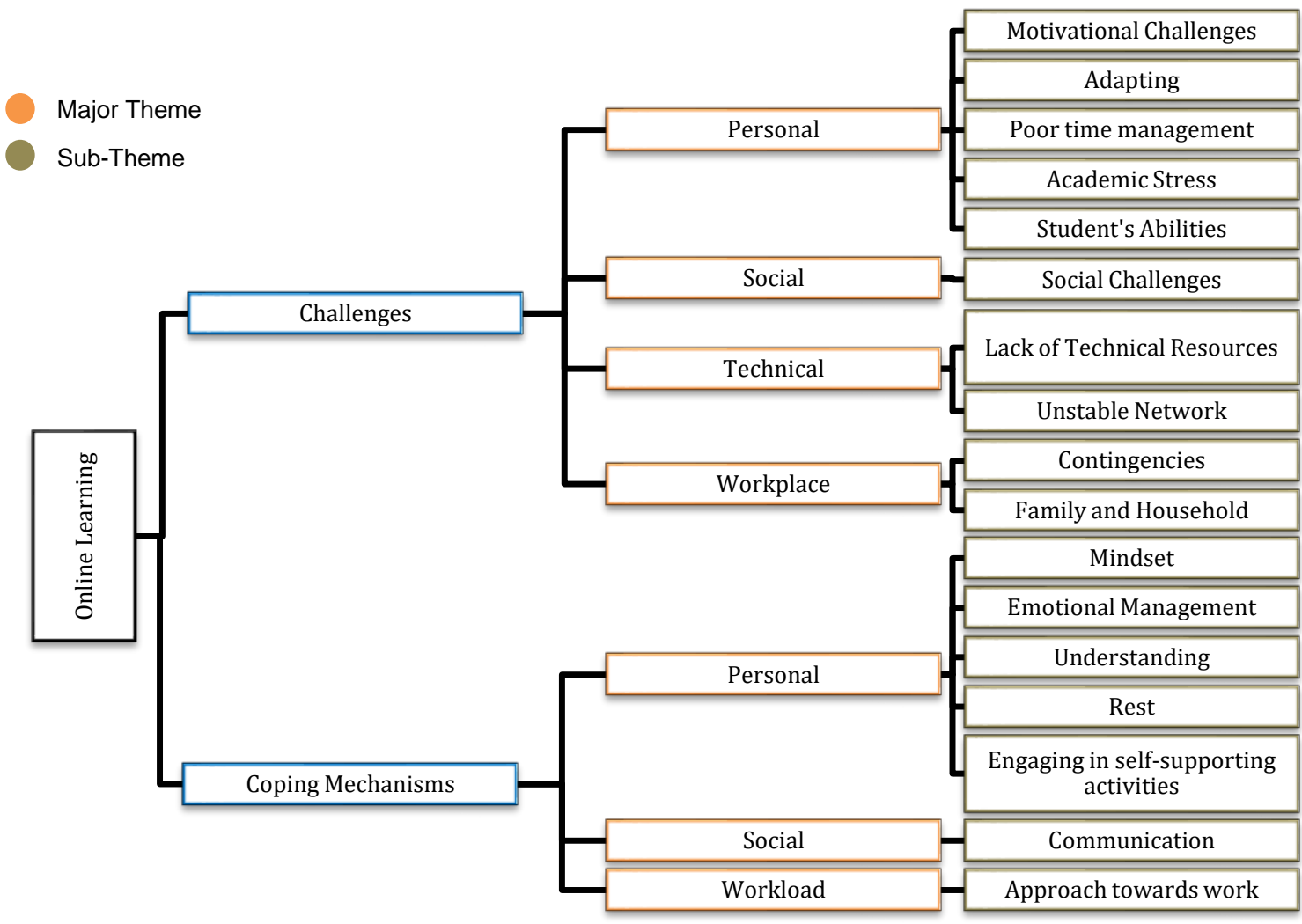

Figure 1.0 The map shows the challenges and coping mechanisms of LNU-ILS senior high school students in an online learning set-up.

This pandemic has vastly deranged the education of students. With this new system to adapt to, research findings show that fully adapting to this new online learning system would need a handful of mental, physical, and financial preparations to adjust to the students' learning deficit. The differences in resources, support, and capacity of each student have caused a significant range of challenges to the students.

Through a focus group discussion, the researchers were able to gather data that was then processed through the thematic analysis method. The researchers were able to identify four major themes which are: personal, social, technical, and workplace challenges.

The personal challenges consist of five sub-themes specifically: motivational challenges, adapting, poor time management, academic stress, and student's abilities. Under the Social theme is a sub-theme social challenge. The Technical challenges include two sub-themes which are lack of technical resources and unstable networks. While in the workplace challenges are the sub-themes: family and household and contingencies.

Three major themes of coping mechanisms were also identified which are: Personal, social, and workload. Under the personal theme are 5 sub-themes namely: mindset, emotional management, understanding, rest, and engaging in self-supporting activities. While in social includes communication, and in workload is approach towards work.

Below are the following descriptions of the sub-themes of both the coping mechanisms and challenges of the senior high school students: 


\section{Challenges}

4.1 Personal (Major Theme)

\subsubsection{Motivational Challenges}

The student participants were facing a significant challenge in their everyday motivation. Students experience a lack of motivation and interest in learning. They started to question their purpose of studying, stating, "Feeling ko ginhihimo ko nala ini kay kailangan, bagan dre ko na nakikita an purpose kun kayano ako nag eskwela from the start," "nawawarayan kana hin purpose," and "started to feel more lazy and unmotivated". A significant change in their behavior towards their learning greatly affected their performance in school, causing them to be lazy, produce low-quality outputs, and overdue tasks.

\subsubsection{Adapting}

With this new learning system to adapt to, senior high school students of LNU-ILS are still having a hard time adapting to this new mode of learning even for almost a year and a half of implementing it. One of the participants even mentioned that, and I quote, "it's very hard to be this independent". The new system also concerns the personal spaces of the students. According to the student participants, many video presenting tasks were assigned to them that intensified their discomfort, stating, "nauulang tim personal space kay kailangan mo ini himuon biskan na dire kaman.” Research studies found that online learning required adequate mental, physical, and financial preparations to adjust to the students' learning deficit.

\subsubsection{Poor Time Management}

Most of the student participants of the study were significantly struggling in managing their time and schedule. With the heavy workload given to them, the students were also facing personal problems in their households and unexpected events they can't control. One student said, "sometimes you can't actually control time itself and your schedule." The students even stated that tasks were given to them even not during the given schedule. The tasks were too handful to be completed with the time set out for them. It has caused the students to pass requirements late and a backlog of workload.

\subsubsection{Academic Stress}

Most of the student participants find online learning very stressful. It widely affects their mental and emotional health and their everyday behavioral mood. Factors that affect their stress level are deadlines, workloads, and the different challenges they are experiencing in general. As the participants stated, "my two challenges were time management and kuan stress," and you won't get anything done because of the stress."

\subsubsection{Student's Abilities}

The students' abilities were also a challenge in this online learning modality. As one participant stated "nadepende hit tao (student) kun makakaya niya." The students have their strengths and weaknesses. Without the support of their classmates, it was hard for them to be independent on their own.

\subsection{Social (Major Theme)}

\subsubsection{Social Challenges}

Social challenges were encountered by the participants in this online learning set-up, students were forced to be independent and not rely on other people. However, the participants encountered a lack of connection among students and teachers for they were not used to being independent. One of the students stated, "My problem was the unavailability of my members in group activities. Messaging them almost every hour, just to make sure that they're doing the task." Lack of communication, cooperation, and unavailability of the students in a grouped activity was one of the challenges that were observed in this new system, most students in a grouped activity don't do their assigned tasks. 
4.3 Workplace (Major Theme)

\subsubsection{Contingencies}

Unexpected events may happen at any moment of our lives, the participants experienced incidents that were out of their control. The participant has experienced unexpected events and it was difficult for a student. "What I find most difficult is contingencies, or the unexpected events dito sa bahay," the participant mentioned.

\subsubsection{Family and household responsibilities}

Other than school activities, students also have responsibilities at home. The participants have experienced moments where family and household responsibilities were prioritized rather than the schoolwork. These events may occur unexpectedly. Most students prioritize household responsibilities more than their academics, some stating, "it scales up with our work in our house as well which leads to many things done today as to more problems" The participants are students and also a child with responsibilities at home that have surely affected school priorities.

\subsection{Technical (Major Theme)}

\subsubsection{Lack of technical resources}

The lack of technical resources has built a barrier and obstacle to students. "I think that students will have a hard time connecting or understanding things in class," the participant stated. Having a laptop, mobile phone, computer, and other technical resources is one of the most significant equipment in online learning. Some of the participants faced issues in technical resources because not everyone has the privilege to provide themselves with essentials for the online class. We all know that these technical resources will make student's school life not easier but better.

\subsubsection{Unstable network}

A reliable internet connection offers a lot of conveniences and allows us to complete tasks with much less hassle, whether it's submitting schoolwork or attending classes. Students won't struggle to pass schoolwork and attend classes on time. With a stable internet connection, students won't miss any schoolwork or classes and students will not go beyond the deadline. But it may be the total opposite with the situation of some students who were facing a lot of troubles with their internet connection, stating "motivation to attend online classes and stable internet connection. These are some of the problems that we face."

\section{Coping Mechanisms}

\subsection{Social (Major Theme)}

\subsubsection{Communication}

Sometimes, group activities are given to the participants. The participants find this task often challenging, especially in terms of communication, like the unavailability of the members during a meeting. According to the data gathered, the participants' way of coping with this challenge is by, and I quote exactly, "messaging them almost every hour". They resort to keeping the connection between groupmates steady and active.

\subsection{Personal (Major Theme)}

\subsubsection{Mindset}

The participants' one way of coping is through coping with their challenges by themselves, Student's approach challenges with a positive mindset where some of them motivate themselves. In the data gathered, one of the participants stated, "I try to focus and get on with my tasks while doing all those things and do my responsibilities here at home and stay away from negativity." 


\subsubsection{Emotional Management}

Students have this part in schooling where they overthink and feel unmotivated, to overcome this challenge, students recognize and validate their feelings. And with the data gathered, one of the participants stated, "My coping mechanisms are accepting and feeling it."

\subsubsection{Understanding}

According to most of the student participants in the study, understanding one another is a must. "Ginhahabaan ko nala tak pasensiya tas bagan dire nala ako magiging strict kaduro kay maaram man liwat ako it kabutangan naton yana," the participant stated. With the people surrounding them, they try their best to understand and be patient with one another knowing this pandemic can be tough to each one of us.

\subsubsection{Rest}

The participants have stated that being new to this new normal is natural for we did have to transit from going to school to conducting online classes. One of the participants mentioned "don't overwork". According to them, since we are new to this, we do get tired, especially when we focus more on our gadgets. Resting is one of the coping mechanisms the participants have for this challenge. Taking a break from a long period of doing work is needed for the students.

\subsubsection{Engaging in Self-Supporting Activities}

One of the coping mechanisms that the participants stated is about engaging yourself to do activities to calm your mind, "Do something else makukuhaan ko hin esteem or motivation," it stated. Engaging in other stuff after studying makes our mind relaxed especially when we engage ourselves to do the things we usually do like our hobbies where we can also find motivation and gain our esteem back.

\subsection{Workload (Major Theme)}

\subsubsection{Approach Towards Work}

The participants are often challenged with loads of tasks, deadlines, and missed classes. In coping with these challenges, the participants think up of various ways to make it easier for them to ease the weight of their overall workload. One student participant would approach the tasks in a simple way, doing it, and I quote, "stepby-step". The others would try to at least give the task an attempt, while those who missed classes find time to re-understand missed lessons. These participants find ways to ease their workload.

\section{Conclusion}

The researchers identified that the senior high school students of LNU-ILS are struggling in their (1) Personal: Motivational challenges, adapting to the system, poor time management, academic stress, and differences with their abilities or capacities. (2) Social Challenges: lack of communication and cooperation. (3) Technical: Lack of technical resources and unstable network. (4) Workplace: Family and household responsibilities and contingencies. With these challenges comes mechanisms of students to cope with it by (1) Social: through communicating with classmates and friends. (2) Personal: A change in mindset, emotional management, understanding, resting, and engaging in self-supporting activities. (3) Workload: students set out personally efficient approaches towards their workload. 


\section{References}

Anderson, R., Heesterbeek, H., Klinkenberg, D., \& Hollingsworth, T. (2020). How will country-based mitigation measures influence the course of the COVID-19 epidemic? The Lancet, 395(10228), 931-934. doi: 10.1016/s0140-6736(20)30567-5

Amadora, M. G. (2020). Common Problems that Occur During Online Classes. Manila Bulletin News.

Algorani E. \& Gupta V. (2021). Coping Mechanism. NCBI https://www.ncbi.nlm.nih.gov/books/NBK559031/

Barrot, J.S., Llenares, I.I. \& del Rosario, L.S. Students' online learning challenges during the pandemic and how they cope with them: The case of the Philippines. Educ Inf Technol (2021). https://doi.org/10.1007/s10639-021-10589-x

Browning, M., Larson, L., Sharaievska, I., Rigolon, A., McAnirlin, O., \& Mullenbach, L. et al. (2021). Psychological impacts from COVID19 among university students: Risk factors across seven states in the United States. PLOS ONE, 16(1), e0245327. doi: 10.1371/journal.pone.0245327 https://journals.plos.org/plosone/article?id=10.1371/journal.pone.0245327

Chriscaden K. (2020). Impact of COVID-19 on people's livelihoods, their health and our food systems. World Health Organization. https://www.who.int/news/item/13-10-2020-impact-of-covid-19-on-people's-livelihoods-their-health-and-our-food-systems

Cimanes, D. R. (2017). Stress Coping Mechanism and Its Impact to their age among Senior High School students at Parañaque National High School-Baclaran. International Journal for Innovative Research in Multidisciplinary Field, Volume 3, Issue 7, 2.

Clarke, V. B. (2006). Using thematic analysis in psychology. Qualitative Research in Psychology, 1-4.

DepEd. (2020). Briones welcomes 24.7M learners for SY 2020-2021, declares opening of classes a victory. Department of Education Government Philippines.

Dr. Christopher Yaw Kwaah, G. E. (2017). Stress and Coping Strategies among Distance Education Students at the University of Cape Coast, Ghana. Turkish Online Journal of Distance Education, Volume: 18 Number: 3 Article 8, 1-15.

Ekiokenegha O. Lucky, F. A. (2015). Personal Problems and Coping Mechanisms of NIMASA Scholars in Lyceum International Maritime Academy . Asia Pacific Journal of Maritime Education, Vol. 1, No. 2, 4-5.

Elshami, W., Taha, M., Abuzaid, M., Saravanan C., Kawas, S., Abdala, M. (2021) https://www.tandfonline.com/doi/full/10.1080/10872981.2021.1920090?scroll=top\&needAccess=true

Gupta, S. (2017). Ethical Issues in Designing Internet-Based Research: Recommendations for Good Practice. Journal of Research Practice Volume 13, Issue 2, Article D1, 3-10.

Hamza, C. A., Ewing, L., Heath, N. L., \& Goldstein, A. L. (2021). When social isolation is nothing new: A longitudinal study on psychological distress during COVID-19 among university students with and without preexisting mental health concerns. Canadian Psychology/Psychologie canadienne, 62(1), 20-30.

Introduction to Online Teaching and Learning (2021). Retrieved 31 July 2021, from http://www.wlac.edu/online/documents/otl.pdf

Logel, C., Oreopoulos, P., \& Petronijevic, U. (2021). Experiences and Coping Strategies of College Students During the COVID-19 Pandemic. doi: 10.3386/w28803 https://www.nber.org/papers/w28803

Madarang, C. R. (2021). New poll says unstable internet remains top challenge in distance learning. Interaksyon Philstar.

Mahyoob, M. (2020). Challenges of e-Learning during the COVID-19 Pandemic Experienced by EFL Learners. Arab World English Journal (AWEJ), Volume 11. https://files.eric.ed.gov/fulltext/EJ1287713.pdf

Mohammed Amin Almaiah, A. A.-K. (2020). Exploring the Critical Challenges and Factors Influencing the E-learning System Usage during COVID-19 Pandemic. Education and Information Technologies 25:5261-5280, 1-20.

Muslimin, A., \& Harintama, F. (2020). Online Learning during Pandemic: Students' Motivation, Challenges, and Alternatives. Loquen: English Studies Journal, 13(2), 60. doi: 10.32678/loquen.v13i2.3558

Petroski, D. J., \& Rogers, D. (2020). An examination of student responses to a suddenly online learning environment: What we can learn from gameful instructional approaches. Journal of Literacy \& Technology, 21(2).

Simbulan, N. P. (2020). The Philippines - COVID-19 and Its Impact on Higher Education in the Philippines. The Head Foundation Organisation.

Staff, C. P. (2020). Luzon-wide lockdown extended until April 30 to stop COVID-19 spread. CNN Philippines.

Students continue to be stressed about college, their futures. (2021). Retrieved 19 July 2021, from https://www.insidehighered.com/news/2020/10/15/students-continue-be-stressed-about-college-their-futures

Stress And Coping Strategies Among Distance Education Students at The University Of Cape Coast, Ghana (2021). Retrieved 31 July 2021, from https://files.eric.ed.gov/fulltext/EJ1147588.pdf

Sultan, R. M. (2018). Problems Encountered, Coping Mechanism and Behavioral Changes of Selected Internally Displaced Meranaw High School Students. Advances in Social Science, Education and Humanities Research, Volume 269, 1-7. 
Talabong, R. (2020). Metro Manila to be placed on lockdown due to a coronavirus outbreak. Rappler COVID-19.

The challenge facing schools and pupils. (2020). Retrieved 18 July 2021, from https://www.mentalhealth.org.uk/coronavirus/returningschool-after-lockdown/challenge-facing-schools-pupils

Rachael Njeri Kibuku, D. O. (2020). E-Learners' Challenges and Coping Strategies in Interactive and Collaborative e-Learning in Kenya. Journal of Education and Training Studies, Vol. 8, No. 11, 1-12.

Rodriguez-Planas, Nuria, COVID-19 and College Academic Performance: A Longitudinal Analysis. Available at SSRN:

https://ssrn.com/abstract=3789380 or http://dx.doi.org/10.2139/ssrn.3789380 